\title{
English Language Identity Representation through Conflict Interaction
}

\author{
Oksana N. Gnezdechko
}

Tamara I. Leontieva

Olga V.Filippova

Vladivostok State University of Economics and Service; Email: Oksana.Gnezdechko@vvsu.ru

\section{Doi:10.5901/mjss.2015.v6n5s3p147}

\section{Abstract}

The paper provides a comprehensive review of English language identity representation that is evident from pragmatic and psycholinguistic distinctive traits revealed through its discursive image within conflict interaction. The research highlights pragmatic types of conflict interaction and defines specific speech repertory of strategies and tactics employed by the characters depicted in contemporary fictional texts. Specified here is the entity of invective, its quantitative parameters being defined. Functional peculiarities of verbal and non-verbal means of communication have been studied in detail. The specificity of their frequency in the pragmatic types of the English conflict interaction has been considered. Emphasized in the investigation is the psycholinguistic nature of such interactive communication phenomena as communicative conflict, strategies and tactics. The typology of language identities has been elaborated on the basis of communicative strategies analysis. As a result of the research, three-level communicative competence classification has been developed based on the ground of the English language identity's ability of constructing cooperative interactive communication.

Keywords: language identity, conflict interaction, invective.

\section{Introduction}

In recent years, researchers have become increasingly interested in the problem of effective communication. According to H.P. Grice, effective communication has a conventional and intentional impact on the listener from which the recipient recognizes the speaker's intention. Suggested by H.P. Grice "principle of cooperation" prescribes accomplishment of "communication maxims" aimed at achieving effective communication (Grice, 1975, p. 225).

As researchers note, "the principle of cooperation" is observed only in "socially neutral communication", and it presents "an ideal communicative situation (Fadeeva, 2000, p. 6-7). Conflict speech situation is characterized by disregarding conversational maxims of quality and quantity and politeness maxims (Leech, 1983, 75). Modern researchers of conflict dialogue aim to create a linguistic model of conflict verbal interaction which, in turn, requires systemic analysis. Expansion paradigm theory about conflict communication ontology determines the urgency of this article.

The object of the research is conflict speech situations of quarrels and everyday squabbling generated by native speakers (as a certain type of language personalities). The linguistic corpus of the study encompasses 414 discursive segments of Anglo-American fiction involving psychological thrillers by Stephen King, the novel "Gone Girl"by Gillian Flynn.

The purpose of the study is to ascertain verbal and nonverbal characteristics of conflict discourse by identifying its lexico-grammatical, stylistic components, and pragmatic guidelines of discourse participants. According to the objectives we carried out an analytical review of the research concepts and approaches to the study of non-standard communicative situations in terms of psycholinguistic approach to conflict study.

When the principles of communication are violated the cooperative interaction can turn into non-cooperative one, whereby a non-standard communicative situation may emerge (Kluev, 1998, 9). This paper specifies the notion of communicative conflict as a non-standard communicative situation, which contains elements of psychological strain. A communicative conflict could be defined as speech clash that is based on aggression realized by linguistic means (Gnezdechko, 2007, p. 39-40). A non-standard communicative situation, thus, contains signs of deviations from the standard, etiquette, language, rhetoric arrangements (settings), including H.P. Grice's Principles of efficient cooperation or G. Leech's interpersonal rhetoric. Terms of speech communication duplicate or modify Grice's "speech maxims"(Grice, 
1975, p. 225).

In conflict development speech behavior falls into "two opposite programs which contradict each other as a whole but not as separate items" (Rozdestvenskij, 1992, p. 35). These communication programs define the choice of conflict vocal strategies and corresponding speech tactics, which are marked for communicative intensity.

It is important to emphasize that in situations with neutral psychic background the language identity can easily control his/her speech, agreeing its organization with given intentional parameters. But if the situation is aggravated with a high emotional charge a person's thinking refuses to behave normally in an alien for him/her speech situation (Gnezdechko, 2007, p. 41-42). A person's psyche being self-sufficient depresses the process of thinking (ibid.), and in the majority of cases the language identity will exhibit stereotypical (distinctive) signs of his/her social belonging.

\section{Literature Review}

Conflict is a complex and multiple-aspect phenomenon. Studies of conflict interaction are made within the frames of such sciences as philosophy, political studies, sociology, psychology, pedagogy, and others. Scholars are making efforts to find effective ways of harmonizing human relations, including the process of communication

Communication in terms of linguistic can be treated as "passing a message or transfer of utterance content by means of language" (Kuznetsov, 2014; Matveeva, 2010). Researchers more than once accentuated the fact that the interlocutors' interests in the interaction may be different and can lead to contradictions and rivalry, so speech communication should be assessed from the viewpoint of the participants of speech activity (speaker and listener) (Stepanov, 2006, p. 138).

Of particular interest for us is the type of an individual with rough-static attitude. The theory of attitude offered by Georgian scholars (Drizde, 1984; Norakidze, 1975; Uznadze, 1961) is an important organizational link in the research of a language identity in speech communication. Such a person is characterized by external and inner conflicts, deep and intensive emotions, which are realized in speech interaction via conflict speech strategies. A person of this type is disposed to domination in communication; he/she is concentrated on him/herself in utterances. Such an individual is prone to self-analysis, to themes of morality, to the violation of the dialogue coherence, to a conflict clash of intentions (Uznadze, 1961, p. 121-124). On the basis of the above-stated one can infer that the communicative type described can be defined as conflict, or confrontation type.

Speech conflict is, first of all, a speech act, that represents the smallest unit of communication. Speech conflict is the state of opposition between two (or more) members of communication. As a result, each party acts against the other expressing its attitude by verbal and pragmatic means (Tretyakova, 2003, 28).

A comprehensive analysis of conflict dialogues allows pointing out a whole gamut of verbal means: at morphological, lexical, phraseological and syntactic levels (Leontieva, 2012, p. 201). This idea is developed by 0. Filippova who characterizes the language of a conflict dialogue by the use of certain stereotyped logical, syntactic and stylistic structures (Filippova, 2013).

There are many different classifications of linguistic personas, the character and content of them determines the choice of strategies and tactics of discourse construction, fiction included. Scholars describe him/her as communicative/non-communicative, conformal/ non-conformal, cooperative/non-cooperative, even-tempered/emotional (Sukhikh, Zelenskaja, 1997, p. 69), conceptual-logical/associative-fictional (Baranov, 1997, p. 17), etc. Subject to the observance of cooperation principles, speech politeness and etiquette, two types of language identity - authoritarian and non-authoritarian (Gnezdechko, 2005, p. 12-13) could be distinguished.

Following Professor K. Sedov, we point out invective, courtly, and rational-heuristic types of language identities in non-standard vocal situations based on the analysis of conflict interaction speech strategies (Gnezdechko, 2007, p. 41; Zolotarenko, 2009, p. 59-62). This investigation testifies that invective, courtly, and rational-heuristic speech aggressions differ on the linguistic means of their realization quite vividly.

Conflict interaction of communication members is effective within the communicative situation (Gorelov, Sedov, 2001, p. 430). Pragmatic traits of a language identity become evident in a specific choice of communicative strategies and tactics, which show in peculiar communicative styles of the speaker.

Besides, we realize that sometimes the variety of approaches to the problem causes lack of unique, generally recognized, terminological apparatus. As a result, there is a great deal of similar or identical concepts and terms: communication failures/malfunction, poor communication in different studies. The issue of effective communication and the emergence of disruptions in communications have been discussed in home (Adler, 1997; Arutunova, 1998; Arutunova, 2003)as well as foreign linguistics (Searle, 1969). 


\section{Methods and Materials}

Focused on the communicators' strategy intention and tactical moves, illocutionary potential of the English-speaking characters' discourse can be revealed in the research through pragmatic and semantic analysis in conjunction with componential, distributional, contextual and interpretative methods. The research methodology of the language identity manifestation via conflict interaction implies a stagewise analysis:

a) to draw on the Anglo-American fictional texts discursive segments selected with the help of conflict interaction signals;

b) to determine the language identity types;

c) to establish strategies and tactics employed by the interlocutors in the process of conflict interaction construction with regard to theoretical and practical pragmatic implications particularly well suited to these type of task;

d) to calculate the 'invective' notion quantitative parameters resulted in the 'invective' lexical- semantic organization with the field theory applied;

e) to determine the statistical frequency of nominative and communicative units used by a certain language identity type with the lingual-statistical analysis employed.

To investigate the content-related aspect of lingual units with regard to their lexical-semantic field organization the most efficient serves to be the componential method with distributional, functional, contextual and interpretative techniques applied.. This method proved to be efficient for splitting the meanings into constituents called semes, or: markers.

From the viewpoint of the componential analysis of special essence is the core and margin approach to the lexicalsemantic field construction with regard to each seme belonging in the semantic componential. The evidence suggest that a specific weight in the semantic componential structure could be determined by the statistical frequency of the correlative words combined with the word analysed. Hence, the componential analysis could presumably be applied not in its pure form, but in conjunction with distributional and statistic-linguistic methods.

\section{Findings and Discussion}

Originally a case study of the psychological thrillers by Stephen King "The Shining", "Cujo" тa "Misery", novels by U.S. Maugham "Theatre" and Judie Picoult "Harvesting the Heart" makes attempt to analyse burning issues of conflict interaction in the realm of psycholinguistic conflictology.

Psycholinguistic conflictology has gained general acceptance as social psycholinguistics domain intended to harmonize human speech interaction. Lingual implications of conflict interaction explicate the characters' hidden intentions through lexical and syntactical language levels.

As exemplified in the English-speaking novels by Stephen King the findings described in the paper confirm the demarcation lines drawn between invective, courtly and rational-heuristic language identity types compared on the ground of lexical-grammatical, stylistic and pragmatic signals with regard to the speakers psychoemotive distinctive features. The evidence provides observations (Gnezdechko, 2007, p. 40-41), invective, courtly and rational-heuristic speech aggression in accord with lingual means of its realization strictly differ. The first type can be characterized by a direct verbal aggression; the second - by an offence emotion and taste for etiquette, the third - by a common sense and irony. The invective type of the language identity in conflict interaction demonstrates reduced probability of significance: communicative manifestations reflect emotional and biological responses $\breve{~}$ and give rise to the discharge affect through abuse or quarrel. The courtly language identity can be presumably characterized by higher than normal semiotics, predetermined by the taste for etiquette forms of social interaction. The rational and heuristic one - in conflict situation draws from the deliberativeness and common sense.

The rational and heuristic strategy discourse implies a delicate, flexible impact on the addressee's volition. The rational and heuristic language identity employs subtle hints tactics, authoritative avoidance of communication, selfdefence, an attempt to balance (neutralize) the conflict situation. In speech realization it is manifested through standard vocabulary use, neutral speech acts (expressive, requestives, comissives), utterances compression.

Percentage-based cost relationship between stylistic devices can be manifested by invective and rational-heuristic language identity types respectively, where 100\% - total amount (inventory) of stylistic devices used by each particular language identity type (as can be seen from Table 1): 
Table 1 - Overall Percentages of stylistic devices as external attributes of invective and rational-heuristic language identity types

\begin{tabular}{|l|c|c|c|c|c|c|}
\hline Language identity type & Inversion & Rhetorical questions & Repetitions & Exclamatory Sentences & Pauses & Totally \\
Invective & $4 \%$ & $9 \%$ & $16 \%$ & $48 \%$ & $23 \%$ & $100 \%$ \\
Rational-heuristic & - & - & $9 \%$ & $43 \%$ & $48 \%$ & $100 \%$ \\
\hline
\end{tabular}

For the purpose of the invective strategy speech realization involved are emotive lingual means whose organization corresponds to the direct effect on the the addressee's volition and affection.

In going from some quarrel to a row more and more frequent is getting the occurrence of pragmatic maxims violation, which highly depends upon the degree of emotional strain of the situation. The higher the emotional tensity of the situation is, the stronger disregarding of pragmatic maxims the interlocutors admit of. Likewise, the more vivid become Politeness Principles and maxims violation. The shift of the situation into the affect is accompanied by the obscene words tabooed by the conventional English-speaking community. Let's consider the example:

(1) "It has no nobility!" she cried suddenly, jumping and almost spilling beef-barley soup on his white, unturned face.

"Yes," he said patiently. "I understand what you mean, Annie. It's true that Tony Bonasaro has no nobility. He's a slum kid trying to get out of a bad environment, you see, and those words ... everybody uses those words in -"

"They do not!" she said, giving him a forbidding look. "What do you think I do when I go to the feed store in town? What do you think I say? "Now Tony, give me a bag of that effing pigfeed and a bag of that bitchy cowcorn and some of that Christing ear-mite medicine"? And what do you think he says to me? "You're effing right, Annie, coming right the eff up"?"

She looked at him, her face now like a sky which might spawn tornadoes at any instant. He lay back, frightened. The soup-bowl was tilting in her hands. One, then two drops fell on the coverlet.

"And then do I go down the street to the bank and say to Mrs. Bollinger, "Here's one big bastard of a check and you better give me fifty effing dollars just as effing quick as you can"? Do you think that when they put me up there on the stand in Den -" (Misery, 22).

In the dialogue given one of the interlocutors - Eni Wilks - verbalizes his "outburst" by the tactics of rhetorical questions, duplication of the interrogative grammatical structure (What do you think I do when I go to the feed store in town? What do you think I say? What do you think he says to me?), exclamatory sentences (It has no nobility! They do not!), invectives (effing pigfeed, bitchy cowcorn, Christing ear-mite medicine, bastard), repetition of invective vocabulary (effing pigfeed, effing right, eff up, effing dollars, effing quick), incompleteness of the utterances that signals about the speaker's exceeding emotionality. The invective type of the language identity is inclined to employ the tactics of reprimands, strict orders and forbidding, confirmation of one's grip (authority) over the interlocutor, aggressive browbeating, humbling (loss of face), ironical sweet talk, improperly accusation, rhetorical questions, strict interrogation.

It is not a secret that human communication, especially conflict one is full of concealed meanings. According to H.P. Grice, what a speaker means by an utterance may be quite different from what he says. The linguist even coined a new verb - "to implicate" especially to denote the real meaning of an utterance. Thus, the difference between direct and indirect communication comes up. Here is an extract from the novel "Gone Girl" by Gillian Flynn.

The character of the Nick Dunne is at the police station. He constantly quarrels with policemen, pretending indignation and dictating his rules. The scene portrays Nick at the moment when his father who has fled from the lunatic asylum is brought to the same police station. He reacts to the question of the police officer very nervously.

\footnotetext{
"What's going on?" I asked her. "This is my father."

"You got our call?"

"What call?"

"To come get your father." She overenunciated as if I were a dim ten-year-old.

"I - My wife is missing. I've been here most of the night."

She stared at me not connecting in the least.

"I've been right here," I said. "Right goddam next door, how did no one put this together?"

Bitch, bitch, bitch, said my dad.

"Sir, please don't take this tone with me."

Bitch bitch bitch. (Gillian Flynn, pp. 68-70
}

We begin from the description of the situation in which communication occurs. Both, direct and indirect speech acts, demand additional interpretation on the part of the addressee. The conversation happens at the police station; direct 
communication is easily inferred: the character (Nick) feels indignant why his position in this very serious situation for him should not be understood. A clash of intentions is taking place and at the time, it is not in favor of Nick. Conjecture or creative interpretation of the protagonist's speech characteristics consists in conventional understanding of his nervous psychological state, which is proved by ever asking new questions, stammering, emotional stressing separate words (they are marked by the author's italics), and using curse words (goddam, bitch). Obstacles in communication are of psychosomatic nature. The police officer is clearly reluctant to deal with the psychologically abnormal man.

Our analysis will be richer with linguostylistic observations, which function within the theory of indirect communication (Dementyev, 2006). The value of this theory is in the fact that the interpretation of the speaker's words demands additional mental efforts, which causes the necessity of different approaches to text analysis (text linguistics, style, hermeneutics, cognitive study, discourse analysis). Besides, it is suggestive of creating the algorithm of actions for text analysis.

In the analyzed text, indirect communication is stylistically marked. The author resorts to a simile and an epithet: She overenunciated as if I were a dim ten-year-old (diminution). The author exaggerates the description of the young man (hyperbole overenunciated), and uses a dysphemism "Right god dam next door" that renders Nick's feeling of frustration. It is interesting to find an ironical address "Sir", before a reprimand on the part of the police servant, as a means of emotional impact on the addressee "Sir, please don't take this tone with me." The character's inadequacy shows in Nick's commentary with the abusive tirade Bitch bitch bitch, which is not surprising because he is a real son of his crazy father who pronounces only this word throughout the whole novel. The implicature of this situation is a hostile, ill-disposed attitude of the character to the police, to its actions; Nick even doubts mental abilities of the police workers: "...how did nooneputthistogether?"By his behavior he demonstrates rough-static attitude, i.e. deep and intensive conflict strategies.

The concealed meaning isthe refusal of Nick to take this life at its face value. Why should he respect this police if it neither helps nor defends you? There is another proof of his low opinion of the police officer's foolishness, as she could not guess that Nick was kept in the neighboring room of the police station. That was the reason why he could not come and fetch his father: "She stared at me not connecting in the least. "This misunderstanding caused Nick's aggression and the invective Bitch bitch bitch.

To specify the boundaries of the 'invective' notion this paper attempts to describe its quantitative parameters. For the purpose from Oxford Advanced Learner's Dictionary of Current English edited by A.S.Hornby (...) singled out are the allonyms of 'invective' that give rise to the allonyms of the word allonyms distinguished. The latter could be treated as semes, explicants for the class of semes Invective can be treated as a speech act of the expressive manifistation of aggression aimed at the interlocutor.

The illocutionary potential of the invective could be viewed as directly proportional to the strength of the cultural prohibition on the violation of some norm. The notion of invective is easily to recognize. To specify the boundaries of the 'invective' notion this paper attempts to describe its quantitative parameters. For the purpose from Oxford Advanced Learner's Dictionary of Current English edited by A.S. Hornby we singled out the allonyms of 'invective' that give rise to the allonyms of the word allonyms distinguished. The latter could be treated as semes, explicants for the class of semes. The research has registered syntagmatic chains of the invective allonyms. The word invective corresponds to three stages of the componential analysis of its semantic content, as exemplified in:

1 stage: invective /6/, strong /5/, abusive /4/, attacking /5/, violently /11/.

2 stage: power /7/, body /1/, vigorous /6/, bad /4/, cruelly /3/, fight /1/,energy /4/, force /5/, misery /5/.

3 stage: suffering /4/, dangerous /2/, injury /4/, damage /4/.

The data suggest that attracted to the word 'invective' are allonyms abusive $=0,67$, violently $=0,76$, strong $=0,82$, power $=0,85$, they are the words denoting strength, power, energy, as demonstrated in Table 2:

Table 2 - Nuclear categories invective

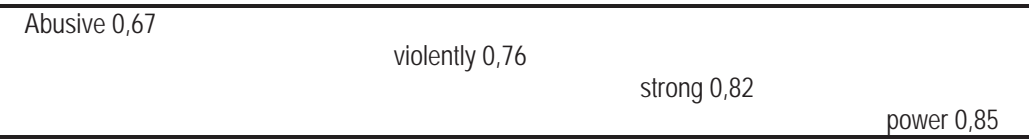

On the periphery there are allonyms cruelly, fight, hurt, harmful comprising semantic content of the word 'invective', its meaningful shades ("evil", "cruel", "harmful), as demonstrated in Table 3. It's not for nothing that Stephen King called one of his psychological thrillers Misery. 
Table 3 - Peripherical allonyms

\begin{tabular}{|l|l|}
\hline Cruelly 1 & Evil 1 \\
Fight 1 & Ruin 1 \\
Hurt 1 & Misery 1 \\
Harmful 1 & Suffering 1 \\
\hline
\end{tabular}

With regard to the type of the speaker's dominant attitude as to the other communicant(s), ability to construct cooperative interactive communication within interpersonal speech interaction serves to be a criterium of the communicative competence levels classification (Gnezdechko, 2007, p. 40). On this ground we distinguish three levels of the communicative competence: conflicting, centered and cooperative.

\section{Concluding Remarks}

As a final point, there will be offered a conclusion involving pragmalinguistic and psychoemotive features of the Englishspeaking conflict interaction with regard to its participants' strategy preferences. The rational and heuristic strategy model implies realization of the pragmatic purpose aimed at the consensus in consideration of Grice's Principles for efficient cooperation.

The invective strategy model, however, is aimed at the emotional sphere of human psyche corresponding to the discourse of speech aggression. The latter's discharged through violation of G.P.Grice's Principles of efficient cooperation and G.Leech's interpersonal rhetoric along with the neutralization of status and role discrepancies. Statistic and lingual analysis allows to reveal the tendencies of stylistically colored, emotionally expressive and non-standard invective vocabulary over non-standard, stylistically neutral speech common to the rational and heuristic language identity.

Finally, the paper provides tentative theoretical and applied implications. However, the findings obtained insufficiently give insight into the problem emphasized. The paper, thus, concludes with a suggestion for further investigation.

\section{References}

Adler, A. (1997). Science of life. http:// lib.kharkov.ua/PSIHO/ADLER/live.txt

Arutunova, N.D. (1998). The Language and the Human World. Moscow: Language of Russian Culture.

Arutunova, N.D. (2003). Sentence and its Meaning: Logico-semantic Problems. (3d ed.). Moscow: Editorial URSS.

Baranov, A.N. and Dobrovolskij, D.O. (1997). The postulates of cognitive semantics. Izvestija Akademii Nauk. Vol. 56, 1 (12-14).

Dementyev, V.V. (2006). Indirect Communication. Moscow: Gnozis.

Drizde, T.M. (1984). Text Activity in the Structure of Social Communication. Moscow: Nauka.

Fadeeva, O.V. (2000). Strategy and tactics of conflict discourse (a study of contemporary English language (Ph.D. thesis). Kiev State Linguistic University, Kiev, Ukraine.

Filippova, O.V. (2013). Lingvopragmatic approach to conflict interaction. The territory of new opportunities. Vestnik of Vladivostok State University of Economics and Service, 15 (37-46).

Flynn, Gillian (2014). Gone Girl. New York: Crown Publishers International Edition.

Gnezdechko, O.N. (2005). Authorization in Scientific Discourse: Communicative-pragmatic Aspect (Based on Articles of modern European and American Linguists). (Ph.D. thesis). Kiev State Linguistic University, Kiev, Ukraine.

Gnezdechko, O.N. (2007). Interpersonal communication in socio- and psycholinguistic aspects. Vestnik LNPU. Philology, 20 (39-47)

Gorelov, I.N., Sedov, K.F. (2001) Introduction to Psycholinguistics. M.: Labirint.

Grice, H. P. (1975). Logic and conversation. Syntax and Semantics, Vol. 3: Speech acts (83-225). L.; N.Y.: Academic Press.

Grice, H.P. (1985). Logic and Conversation. Moscow: Progress.

King , Stephen (1980) Misery. New York: A Signet Book and NAL.

Kluev, E.V. (1998). Speech Communication. Moscow: PREOR.

Kuznetsov, S.A. (1998/2014). Complete Monolingual Russian Dictionary. Thesaurus. St. Petersburg: Norint. http://www.gramota.ru/ slovarilinfo/bts/

Leontieva, T.I. (2012). Lie in the family as the basis for conflict and failure of communication (verbal and non-verbal means of expressing conflict relations). Stereotypes and Creativity in the Text, 16 (191-202).

Leech, G.N. (1983). Principles of Pragmatics. London: Longman.

Matveeva, T. V. (2010). Complete Dictionary of Linguistic Terms Rostov-on-Don: Phoenix.

Norakidze, V.G. (1975) Research Methods of the Personality Character. Tbilisi.

Rozhdestvenskij, Y. (1992). Rhetoric, or How to Avoid Mistakes in Communicating. Groznyj: Book. 
Picoult, Jodi. (2007). Harvesting the Heart. L: Hodder \& Stoughton.

Searle, J. (1969). Speech Acts. An Essay in the Philosophy of Language. London, etc.: Cambridge Univ. Press.

Stepanov, V.V. (2006). Word in the Text. St. Petersburg.

Sukhikh, S.A. \& Zelenskaja, V.V. (1997). Representative Entity of the Person in the Communicative Aspects of the Implementation. Krasnodar. pp. 64-78.

Tretyakova, V.S. (2003). Conflict as language and speech phenomenon. Izvestia of Ural State University, 14 (26-42).

Uznadze, D.N. (1961). The basic assumptions of the attitude theory. Experimental aspects of the psychology of attitude (87-93). Tbilisi,.. Wunderlich, B. (1976). Studien zur Sprechakttheorie. Frankfurt am Main: Suhrkamp.

Zolotarenko, T. O. (2009). Verbal and Nonverbal Aspects of Discursive Representation the English Language Identity (Unpublished master's thesis). Chernihiv Teachers' Training Unversity, Chernihiv, Ukraine. 